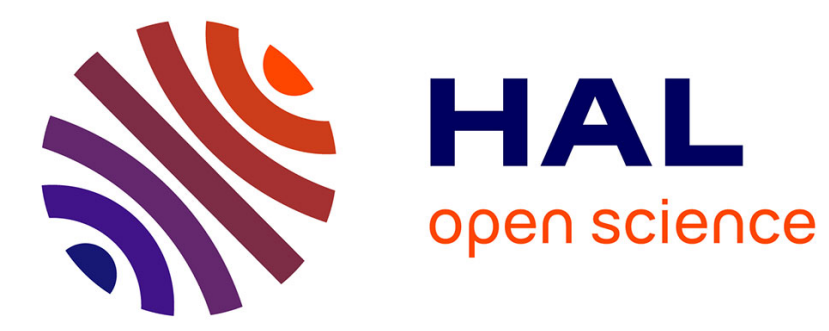

\title{
Robust design of subwavelength grating mirror for mid-infrared VCSEL application
}

Christyves Chevallier, Frédéric Genty, Nicolas Fressengeas, Joel Jacquet

\section{To cite this version:}

Christyves Chevallier, Frédéric Genty, Nicolas Fressengeas, Joel Jacquet. Robust design of subwavelength grating mirror for mid-infrared VCSEL application. Numerical Simulation of Optoelectronic Devices NUSOD 2011, Sep 2011, Rome, Italy. 2 p. - ISBN:978-1-61284-877-8, 10.1109/NUSOD.2011.6041173 . hal-00628591

\section{HAL Id: hal-00628591 \\ https://hal-centralesupelec.archives-ouvertes.fr/hal-00628591}

Submitted on 3 Oct 2011

HAL is a multi-disciplinary open access archive for the deposit and dissemination of scientific research documents, whether they are published or not. The documents may come from teaching and research institutions in France or abroad, or from public or private research centers.
L'archive ouverte pluridisciplinaire HAL, est destinée au dépôt et à la diffusion de documents scientifiques de niveau recherche, publiés ou non, émanant des établissements d'enseignement et de recherche français ou étrangers, des laboratoires publics ou privés. 


\title{
Robust design of subwavelength grating mirror for mid-infrared VCSEL application
}

\author{
Christyves Chevallier*†, Frédéric Genty ${ }^{* \dagger}$, Nicolas Fressengeas ${ }^{\dagger}$ and Joel Jacquet*† \\ *SUPELEC, 2 rue Edouard Belin, Metz, France \\ Email: christyves.chevallier@ supelec.fr \\ † LMOPS, EA 4423, Université Paul Verlaine de Metz, France
}

\begin{abstract}
We present the design of a $\mathrm{Si} / \mathrm{Si}_{3} \mathrm{~N}_{4}$ subwavelength grating mirror optimized for an integration in mid-infrared VCSEL. The definition of a quality factor adapted to VCSEL requirements and maximized by an optimization algorithm allowed us to obtain a polarization selective and high reflectivity structure. The robustness with respect to fabrication error has been enhanced thanks to a precise study of the grating dimension tolerances.
\end{abstract}

\section{INTRODUCTION}

Subwavelength grating mirrors (SGM) made of high index contrast material system can be designed to exhibit very high performances at the 0 -order of diffraction. With only a few layers, SGMs can achieve a reflectivity as high as $99.9 \%$ and bandwidths larger than $100 \mathrm{~nm}$ together with a strong polarization selectivity between TM and TE mode [1], [2]. Such characteristics are very interesting for integration in VCSEL structures where SGM can advantageously replace classical Bragg mirrors. Currently, the wavelength of emission of midIR electrically-pumped VCSEL is limited close to $2.6 \mu \mathrm{m}$ since the necessary semiconductor Bragg mirrors become as thick as $11 \mu \mathrm{m}$ impairing the electro-thermo-optical properties of the device [3], [4]. With a total thickness of less than $2 \mu \mathrm{m}$, the use of SGMs as top mirror should allow VCSEL operation at larger wavelengths.

In this work, we design a $\mathrm{Si} / \mathrm{Si}_{3} \mathrm{~N}_{4} \mathrm{SGM}$ for a VCSEL application at $2.65 \mu \mathrm{m}$. First, the optical properties that VCSEL mirrors must exhibit are defined and quantitatively expressed through a quality factor. The dimensions of the SGM structure are then adjusted by an optimization algorithm to maximize the quality factor and meet VCSEL requirements. Finally, the SGM robustness is enhanced through a precise study of the tolerance on the physical dimensions, to define an error margin that the physical growth process must respect.

\section{MIRROR DESIGN}

Several structures have been designed based on different material combination such as $\mathrm{Si} / \mathrm{SiO}_{2}, \mathrm{Si}_{2} / \mathrm{Si}_{3} \mathrm{~N}_{4}$ or GaAs/ $/ \mathrm{AlO}_{x}$. We present here a $\mathrm{Si} / \mathrm{Si}_{3} \mathrm{~N}_{4}$-based $\mathrm{SGM}$ as shown in Fig. 1. The mirror structure is made of a silicium grating ( $n=3.435)$ on top of a $\mathrm{Si}_{3} \mathrm{~N}_{4}$ layer as the low index sublayer $(n=1.99)$. The $\mathrm{SGM}$ is combined to a $\mathrm{Si}_{2} \mathrm{Si}_{3} \mathrm{~N}_{4}$ quarter wavelength pair in order to increase the total reflectivity [2]. Contrary to Bragg mirrors, SGM design rules to achieve high reflectivity are not straightforward. The values of the etched

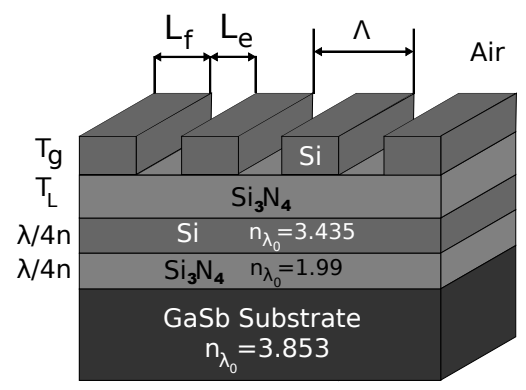

Fig. 1. Scheme of the SGM optimized for $\lambda_{0}=2.65 \mu \mathrm{m}$ exhibiting a $218 \mathrm{~nm}$ large bandwidth with $L_{e}=829 \mathrm{~nm}, L_{f}=522 \mathrm{~nm}, T_{g}=899 \mathrm{~nm}$, $T_{L}=896 \mathrm{~nm}$.

length $L_{e}$, the filled length $L_{f}$, the grating thickness $T_{g}$ and the sublayer thickness $T_{L}$ are thus adjusted thanks to an optimization process to match the expected properties.

The design of mirror for VCSEL application requires to precisely define the optical properties to exhibit. Due to the thin gain region of the VCSEL structure, the reflectivity of the mirror should be as high as $99.5 \%$ for the largest possible bandwidth in order to create a cavity of sufficient quality for laser emission. During the conception, a $99.9 \%$ reflectivity threshold has been chosen to ensure a fabrication security margin. Moreover, contrary to Bragg mirrors, SGM can show a polarization selectivity due to their 1D symmetry. By choosing a minimum reflectivity of $99.9 \%$ for transverse magnetic (TM) mode and a maximum reflectivity of $90 \%$ for transverse electric (TE) mode, laser effect should be possible only in TM polarization and thus should increase the stability of the emitted beam.

The mirror is simulated by the rigorous coupled wave analysis method (RCWA) [5], [6] which computes reflection spectra for TM and TE modes. This method allows us to solve Maxwell equations in a faster way than finite difference based methods such as Finite Difference Time Domain (FDTD) but makes the assumption of a perfectly squared grating with an infinite number of periods. Through a numerical analysis of the computed reflection spectra, the quality of a design is quantitatively evaluated by the use of a quality factor Q [2]:

$$
Q=\frac{\Delta \lambda}{\lambda_{0}} \frac{1}{N} \sum_{\lambda=\lambda_{1}}^{\lambda_{2}} R_{T M}(\lambda) g(\lambda)
$$




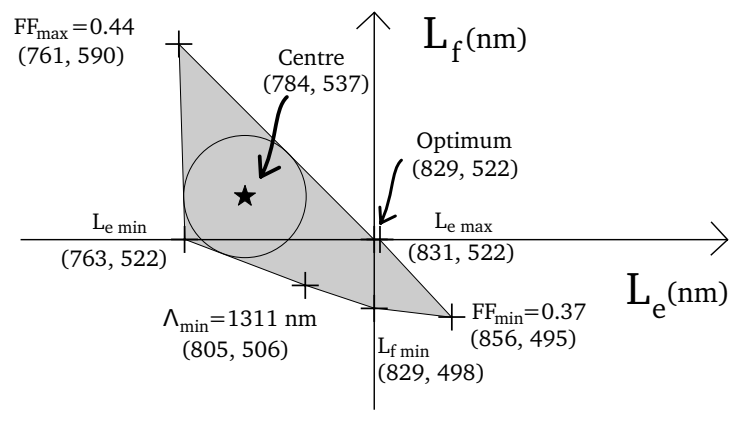

Fig. 2. The tolerance map represents the variation range for the $\left(L_{e}, L_{f}\right)$ couples while keeping $T_{g}$ and $T_{L}$ at their optimum value. The center of the largest incircle of the polygon $(\star)$ indicates the most tolerant point with respect to the fabrication errors on $L_{e}$ and $L_{f}$.

This quality factor is written to take into account the VCSEL requirements with a polarization selectivity performed by selecting the range of wavelengths $\lambda$ around $\lambda_{0}$ for which $R_{T M}$ is higher than $99.9 \%$ and $R_{T E}$ is lower than $90 \%$. The centering of the bandwidth around $\lambda_{0}=2.65 \mu \mathrm{m}$ is made by computing a gaussian weighted average of the $R_{T M}$ values on the $N$ points of the bandwidth $\left[\lambda_{1}, \lambda_{2}\right]$. Finally the influence of the width of the stopband is expressed by multiplying the latter average by the bandwidth itself $\Delta \lambda=\left|\lambda_{2}-\lambda_{1}\right|$ and normalized by $\lambda_{0}$.

\section{OPTIMIZATION}

The optimization of the mirror performance is made by adjusting the grating parameters to maximize the quality factor $Q$. However, with its numerous local maxima, its non linearity, its discontinuity and an unknown derivative, optimizing $Q$ can only be done using a global maximization method. An optimization algorithm [7], the Differential Evolution algorithm [8], has been used to automatically find the best set of parameters which maximizes the mirror quality.

The $\mathrm{Si} / \mathrm{Si}_{3} \mathrm{~N}_{4}$-based structure presented in Fig. 1 has been optimized under constraints which aim to limit the etching process difficulties by using large grooves $\left(L_{f}\right.$ and $L_{e}>$ $500 \mathrm{~nm})$ with a squared shape $\left(L_{e} / T_{g}>0.9\right)$. The resulting optimum grating parameters are $L_{e}=829 \mathrm{~nm}, L_{f}=522 \mathrm{~nm}$, $T_{g}=899 \mathrm{~nm}, T_{L}=896 \mathrm{~nm}$. This mirror design exhibits a $218 \mathrm{~nm}$ large bandwidth with $R_{T M}>99.9 \%$ together with a high polarization selectivity by keeping $R_{T E}<90 \%$ and meets all previously defined VCSEL requirements.

\section{ROBUSTNESS ENHANCEMENT}

In order to evaluate the feasibility of the design, a tolerance study has been performed on the dimensions of the grating. The tolerance of one parameter is defined as the allowed variation range of this parameter for which the mirror is enough performant for a VCSEL application with $R_{T M}>99.9 \%$ and $R_{T E}<90 \%$. The tolerance computation of the structure described in Fig. 1 shows a very robust design with several percent of tolerance on each optimized length.

The map of the variation range of $L_{e}, L_{f}$, the period $\Lambda$ and the fill factor $F F=L_{f} / \Lambda$ (Fig. 2), indicates the area of the $\left(L_{e}, L_{f}\right)$ couples allowed for the design. We only present here the tolerance study of the parameters related to the grating etching which is a critical step of the fabrication process. The optimum point $(829,522)$ with the largest bandwidth found by the optimization algorithm is located at the edge of the tolerance area. Thus, even if tolerances of $8.2 \%$ on $L_{e}$ and $4.6 \%$ on $L_{f}$ are allowed, the accuracy of the fabrication process is very critical with a $L_{f}$ optimum value equals to the upper tolerance limit. So, in order to enhance the robustness of the grating with respect to the error of fabrication which could be made on $L_{e}$ and $L_{f}$, a non optimum point located at the centre of the tolerance area has been chosen.

The resulting design $(784,537)$, with grooves larger than $500 \mathrm{~nm}$ and large tolerance values $\left(5.5 \%\right.$ for $L_{e}$ and $8 \%$ for $L_{f}$ ), exhibits a $186 \mathrm{~nm}$ large bandwidth and seems to be well adapted for integration in a $2.65 \mu \mathrm{m}$ operating VCSEL device.

\section{CONCLUSION}

In this work, the design of a $\mathrm{Si} / \mathrm{Si}_{3} \mathrm{~N}_{4}$ subwavelength grating mirror exhibiting a $186 \mathrm{~nm}$ large $99.9 \%$ high reflectivity bandwidth is presented. The mirror structure has been automatically optimized thanks to the definition of a VCSEL mirror quality factor maximized by an optimization algorithm. The resulting design tolerance has been evaluated and the grating parameters were adjusted to enhance the robustness with respect to the error of fabrication. This mirror, with a thickness of less than $2 \mu \mathrm{m}$, should allow laser operation of VCSEL devices at $2.65 \mu \mathrm{m}$.

\section{ACKNOWLEDGMENT}

The authors thank the French ANR for financial support in the framework of Marsupilami project (ANR-09-BLAN-016603) and IES and LAAS (France), partners of LMOPS/Supélec in this project. This work was also partly funded by the InterCell grant (http://intercell.metz.supelec.fr) by INRIA and Région Lorraine (CPER2007).

\section{REFERENCES}

[1] C. Mateus, M. Huang, Y. Deng, A. Neureuther, and C. Chang-Hasnain, "Ultrabroadband mirror using low-index cladded subwavelength grating," IEEE Photon. Technol. Lett., vol. 16, no. 2, pp. 518-520, 2004.

[2] C. Chevallier, N. Fressengeas, F. Genty, and J. Jacquet, "Optimized sub-wavelength grating mirror design for mid-infrared wavelength range," Appl. Phys. A- Mater, 2010, 10.1007/s00339-010-6059-4.

[3] A. Ducanchez, L. Cerutti, P. Grech, F. Genty, and E. Tournié, "Mid-infrared GaSb-based EP-VCSEL emitting at $2.63 \mu \mathrm{m}$." Electron. Lett., vol. 45, no. 5, pp. 265-267, 2009.

[4] A. Bachmann, S. Arafin, and K. Kashani-Shirazi, "Single-mode electrically pumped GaSb-based VCSELs emitting continuous-wave at 2.4 and 2.6 mm," New J. Phys., vol. 11, no. 12, p. 125014, 2009.

[5] M. G. Moharam, D. A. Pommet, E. B. Grann, and T. K. Gaylord, "Stable implementation of the rigorous coupled-wave analysis for surface-relief gratings: enhanced transmittance matrix approach," J. Opt. Soc. Am. A, vol. 12 , no. 5, pp. 1077-1086, 1995.

[6] H. Rathgen, "mrcwa 20080820," http://mrcwa.sourceforge.net/, 2010.

[7] D. L. Kroshko, “OpenOpt 0.27," http://openopt.org/, December 2009.

[8] V. Feoktistov, Differential Evolution, ser. Optimization and Its Applications, P. M. Pardalos, Ed. Springer US, 2006. 